\title{
The impact of adjuvant treatment with external beam radiotherapy and vaginal brachytherapy on health-related quality of life in patients with early-stage endometrioid endometrial carcinoma - initial results of a prospective study
}

\author{
Adam Kluska1, 2®, Malgorzata Moszynska-Zielinska ${ }^{3}$, Leszek Zytko³, Natalia Tracz' ${ }^{1}$, \\ Bartlomiej Tomasik ${ }^{4} \oplus$, Anna Stanislawek ${ }^{3}$, Jolanta Luniewska-Bury ${ }^{1}$, \\ Jacek Fijuth ${ }^{2,3}$, Leszek Gottwald ${ }^{2,3}$ \\ 'Department of Brachytherapy, Copernicus Memorial Hospital, Lodz, Poland \\ ${ }^{2}$ Department of Radiotherapy, Chair of Oncology, Medical University of Lodz, Poland \\ ${ }^{3}$ Department of Teleradiotherapy, Copernicus Memorial Hospital, Lodz, Poland \\ ${ }^{4}$ Department of Biostatistics and Translational Medicine, Medical University of Lodz, Poland
}

\begin{abstract}
Objectives: Our study evaluates the impact of adjuvant treatment with external beam radiotherapy (EBRT) combined with vaginal high-dose-rate brachytherapy (HDR BT) on health-related quality of life (HRQL) in patients with early-stage endometrioid endometrial carcinoma.

Material and methods: We assessed HRQL of patients based on the EORTC QLQ-C30 questionnaire, with endometrial cancer specific HRQL module - EORTC QLQ-EN24. From March 2019 to April 2020 we enrolled 20 patients with early-stage endometrioid endometrial carcinoma, qualified for adjuvant treatment after hysterectomy. We compared the scores measured with the questionnaires at the beginning and at the end of the treatment.

Results: There was a statistically significant decrease in the mean of global health status/quality of life assessed according to the EORTC QLQ-C30 scale, from $62.25 \pm 13.12$ at the beginning of the adjuvant radiotherapy to $55.85 \pm 14.68$ at the end of the treatment $(p=0.047)$. The mean appetite loss score was higher at the onset of the treatment as compared to its value after EBRT, $19.9 \pm 27.33$ vs $11.6 \pm 19.52(p=0.043)$. Similarly to the mean constipation score, which was $29.85 \pm 30.40$ vs $11.6 \pm 19.52(p=0.013)$. The mean diarrhoea symptom scale increased from $16.55 \pm 20.16$ to $56.75 \pm 36.10(p=0.001)$. In the EORTC QLQ-EN24 scales, gastrointestinal symptoms scores were higher at the end of the treatment, (with the mean of $26.45 \pm 22.76)$ as compared to $14.30 \pm 16.52$ at the beginning of EBRT $(p=0.003)$.

Conclusions: Patients who receive adjuvant radiotherapy have decreased quality of life during the treatment reporting more serious gastrointestinal symptoms. The potential risk of treatment-related toxicity should be taken into account during the treatment planning process in order to minimize the deterioration of HRQL.

Key words: health-related quality of life; endometrial carcinoma; endometrioid; radiotherapy
\end{abstract}

Ginekologia Polska 2022; 93, 3: 195-202

\section{INTRODUCTION}

Endometrial carcinoma is the fourth most common female carcinoma in Poland, with an incidence of $7.3 \%$ of all yearly registered malignant neoplasms in women. It causes $3.9 \%$ of cancer deaths in women in Poland [1]. Pathologically, endometrial carcinoma is divided into two main histological and clinical subtypes: type I - endometrioid adenocarcinoma, which is more common and type II - non-endometroid endometrial carcinoma [2]. Clinicopathological prognostic factors are staging, tumour histology, grading, lymphovascular space invasion (LVSI), depth of myometrial invasion, age and general condition of patients [3,4]. After surgery, 
in patients with type I endometrial carcinoma staged I B with risk factors and at stage II, radiotherapy is the adjuvant treatment of choice [5-8].

In numerous studies in oncological patients, the impact of adjuvant treatment on quality of life has been examined $[9,10]$. In tumors localized in the pelvis, long term outcomes of quality of life after adding adjuvant radiotherapy show increase of adverse urinary and bowel symptoms and lower physical and role-physical functioning, even 15 years after treatment [9]. It is postulated that adjuvant treatment with vaginal high dose rate brachytherapy (HDR BT) provides better long-term health-related quality of life (HRQL) than external beam radiation therapy (EBRT) [10].

The HRQL can be measured using validated questionnaires. In patients with endometrial carcinoma, it can be done with the European Organization for Research and Treatment of Cancer (EORTC) core quality of life questionnaire (EORTC QLQ-C30) with Quality of Life Questionnaire-Endometrial Cancer module (EORTC QLQ-EN24) [11-13]. In the EORTC QLQ-C30 questionnaire, response scales ranging from 1 to 4 points for all items except for items 29 and 30 with response scales from 1 to 7 points. In the EORTC QLQ-EN24 module, response scales are used, all ranging from 1 to 4 points $[12,14]$.

The EORTC QLQ-C30 questionnaire is composed of both multi-item subscales and single-item measures. These in- clude: five functional subscales (physical functioning, role functioning, emotional functioning, cognitive functioning, social functioning), a global health status/QoL scale, three symptom subscales (fatigue, nausea and vomiting, pain) and six single symptom items (dyspnoea, insomnia, appetite loss, constipation, diarrhoea, financial difficulties). The EORTC QLQ-EN24 module is composed of 5 multi-item scales, from which four are used to assess lymphoedema, urological symptoms, gastrointestinal symptoms and body image. In addition, five single items are used to evaluate pain in the back and pelvis, tingling/numbness, muscular pain, hair loss, taste change [14]. The changes in HRQL parameters in patients with type I endometrial carcinoma is still not well defined.

The aim of our study was to prospectively assess the impact of adjuvant radiotherapy on $\mathrm{HRQL}$ in patients with type I endometrial carcinoma staged I-II treated at our institution. In this paper, we present preliminary results of our study.

\section{MATERIAL AND METHODS}

From March 2019 to April 2020, we enrolled 20 patients aged from 58 to 85 (mean $68.15 \pm 6.43$ ) years old with endometrioid endometrial carcinoma staged I-II in FIGO classification. All patients were after total abdominal hysterectomy (TAH). Lymphadenectomy of the pelvis was performed in 11 patients, seven patients had no lymphadenectomy, and

Table 1. Characteristics of patients in the study group

\begin{tabular}{|c|c|c|c|c|c|c|c|}
\hline No. & Age [years] & histology & FIGO stage & Grading [G] & LVSI & TAH & $\mathrm{PL}$ - number of resected lymph nodes \\
\hline 1 & 63 & Endometrioid & $\|$ & 2 & - & + & 21 \\
\hline 2 & 68 & Endometrioid & IB & 3 & - & + & 1 \\
\hline 3 & 69 & Endometrioid & IB & 2 & + & + & 33 \\
\hline 4 & 76 & Endometrioid & IB & 2 & + & + & - \\
\hline 5 & 68 & Endometrioid & IA & 2 & + & + & - \\
\hline 6 & 76 & Endometrioid & IB & 2 & - & + & - \\
\hline 7 & 71 & Endometrioid & IB & 2 & - & + & 12 \\
\hline 8 & 67 & Endometrioid & IB & 1 & + & + & - \\
\hline 9 & 59 & Endometrioid & IB & 2 & + & + & 13 \\
\hline 10 & 66 & Endometrioid & IB & 2 & + & + & - \\
\hline 11 & 67 & Endometrioid & $\|$ & 2 & - & + & 22 \\
\hline 12 & 62 & Endometrioid & $\|$ & 2 & + & + & 18 \\
\hline 13 & 64 & Endometrioid & $\|$ & 2 & + & + & 5 \\
\hline 14 & 85 & Endometrioid & II & 2 & - & + & 19 \\
\hline 15 & 62 & Endometrioid & IB & 2 & + & + & 6 \\
\hline 16 & 58 & Endometrioid & I A & 2 & + & + & - \\
\hline 17 & 67 & Endometrioid & $\|$ & 1 & No data & + & No data \\
\hline 18 & 72 & Endometrioid & $\mathrm{IB}$ & 2 & + & + & 10 \\
\hline 19 & 69 & Endometrioid & IB & 2 & No data & + & No data \\
\hline 20 & 77 & Endometrioid & IB & 2 & No data & + & - \\
\hline
\end{tabular}

FIGO — The International Federation of Gynecology and Obstetrics; LVSI — lymphovascular space invasion; TAH — total abdominal hysterectomy; PL — pelvic lymphadenectomy 
there was a lack of information about lymph node procedure in 2 patients. Detailed data are presented in Table 1. The patients were qualified for adjuvant radiotherapy. The treatment scheme involved the application of EBRT to postoperative bed in the pelvis and regional lymph nodes of a dose up to $44 \mathrm{~Gy}$, fractionated at $2 \mathrm{~Gy}$ daily, five fractions a week in each patient. In EBRT, the irradiated area was marked according to the Radiation Therapy Oncology Group (RTOG) recommendations for adjuvant radiotherapy of endometrial carcinoma at stage I-II. It was not dependent on the number of resected histologically negative pelvic lymph nodes. During EBRT, vaginal HDR BT using vaginal stamps was implemented, fractionated at one application of $6 \mathrm{~Gy}$ or $7.5 \mathrm{~Gy}$ weekly for three weeks up to a total dose of $18 \mathrm{~Gy}$ or $22.5 \mathrm{~Gy}$. The characteristics of the study group are presented in Table 2.

We assessed $\mathrm{HRQL}$ in the study group using the EORTC QLQ-C30 questionnaire [14] with endometrial cancer-specific HRQL module - EORTC QLQ-EN24 [12]. In both the EORTC QLQ-C30 and EORTC QLQ-EN24 questionnaires, the linear transformation was performed to standardize the raw score, so that scores ranged from 0 to 100; a higher score represented the higher intensity of symptoms. Baseline questionnaires were completed at the beginning of treatment and at the completion of EBRT. We compared scores measured with EORTC QLQ-C30 and EORTC QLQ-EN24 at the beginning and at the end of treatment. The first questionnaire was performed during the first week of treatment, before the first application of VBT, the questionnaire at the end of treatment was performed after the last application of VBT, during last three days of EBRT. Written informed consent to participate in the study was obtained from all patients.

All statistical analyses were performed using Statistica 13.1 software (Statsoft, Tulsa, OK, US). The Wilcoxon signed-rank test was used to compare HRQL scores at the beginning and at the end of treatment. The repeated measures ANOVA was used to compare changes in time of EORTC QLQ-C30 scales: global health status/quality of life, appetite loss, constipation, diarrhoea and EORTC QLQ-EN24 scales: gastrointestinal symptoms, urological symptoms and mean pain in the back and pelvis between subgroups. The " $\mathrm{p}$ " values below 0.05 were considered statistically significant. The study was approved by the Bioethics Commission of the Medical University of Lodz No. RNN/98/19/KE.

\section{RESULTS}

There were no statistically significant differences in scores of the EORTC QLQ-C30 functioning scales (physical functioning, role functioning, emotional functioning, cognitive functioning, social functioning) between the onset of treatment and at the end of EBRT (Tab. 3). There was a sta-

\section{Table 2. Characteristics of the study group}

\begin{tabular}{|c|c|}
\hline \multicolumn{2}{|l|}{ Age at enrollment [years] } \\
\hline Median [years] & $68.15 \pm 6.43$ \\
\hline$<60$ years & $2(10 \%)$ \\
\hline $60-70$ years & $6(30 \%)$ \\
\hline$>70$ years & $12(60 \%)$ \\
\hline \multicolumn{2}{|l|}{ FIGO 2018 Stage } \\
\hline FIGO IA & $2(10 \%)$ \\
\hline FIGO IB & $12(60 \%)$ \\
\hline FIGO II & $6(30 \%)$ \\
\hline \multicolumn{2}{|l|}{ Histological grade } \\
\hline Grade 1 & $2(10 \%)$ \\
\hline Grade 2 & $17(85 \%)$ \\
\hline Grade 3 & $1(5 \%)$ \\
\hline \multicolumn{2}{|l|}{ WHO performance score } \\
\hline WHO 0 & $7(35 \%)$ \\
\hline WHO 1 & $12(60 \%)$ \\
\hline WHO 2 & $1(5 \%)$ \\
\hline \multicolumn{2}{|l|}{ Lymphadenectomy performed } \\
\hline Yes & $11(55 \%)$ \\
\hline No & $7(35 \%)$ \\
\hline Missing data & $2(10 \%)$ \\
\hline Median number of resected lymph nodes & $14.55 \pm 9.20$ \\
\hline \multicolumn{2}{|l|}{ Adjuvant Treatment } \\
\hline EBRT 44 Gy in 22 fractions & $20(100 \%)$ \\
\hline Vaginal Brachytherapy $3 \times 6 \mathrm{~Gy}$ & $16(80 \%)$ \\
\hline Vaginal Brachytherapy $3 \times 7.5 \mathrm{~Gy}$ & $4(20 \%)$ \\
\hline \multicolumn{2}{|l|}{ Comorbidity } \\
\hline Diabetes & $6(30 \%)$ \\
\hline Hypertension & $15(75 \%)$ \\
\hline \multicolumn{2}{|l|}{ BMI } \\
\hline$<30$ & $8(40 \%)$ \\
\hline$>30$ & $12(60 \%)$ \\
\hline
\end{tabular}

FIGO - The International Federation of Gynecology and Obstetrics; WHO — World Health Organization; EBRT — external beam radiotherapy

Table 3. Results of QLQ C-30 - functioning scales

\begin{tabular}{|l|l|l|l|}
\hline $\begin{array}{l}\text { EORTC functioning } \\
\text { scales }\end{array}$ & $\begin{array}{l}\text { Start of } \\
\text { treatment } \\
\text { Mean ( } \pm \text { SD) }\end{array}$ & $\begin{array}{l}\text { End of } \\
\text { treatment } \\
\text { Mean }( \pm \text { SD) }\end{array}$ & p value \\
\hline $\begin{array}{l}\text { Global health } \\
\text { status/quality of life }\end{array}$ & $62.25( \pm 13.12)$ & $55.85( \pm 14.68)$ & 0.047 \\
\hline Physical functioning & $69( \pm 15.47)$ & $74.55( \pm 13.02)$ & 0.136 \\
\hline Role functioning & $79.25( \pm 22.08)$ & $77.55( \pm 14.42)$ & 0.594 \\
\hline Emotional functioning & $68.25( \pm 20.29)$ & $73.9( \pm 17.07)$ & 0.117 \\
\hline Cognitive functioning & $77.55( \pm 18.06)$ & $81.75( \pm 20.82)$ & 0.154 \\
\hline Social functioning & $76.75( \pm 25.54)$ & $73.25( \pm 23.22)$ & 0.423 \\
\hline
\end{tabular}

EORTC - European Organization for Research and Treatment of Cancer; $\mathrm{SD}$ - standard deviation 


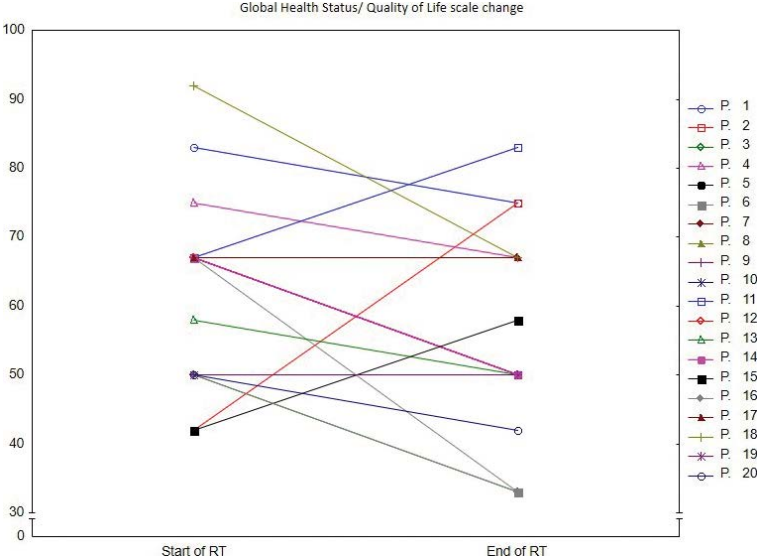

Figure 1. Global health status/Quality of life scale change; RT - radiotherapy

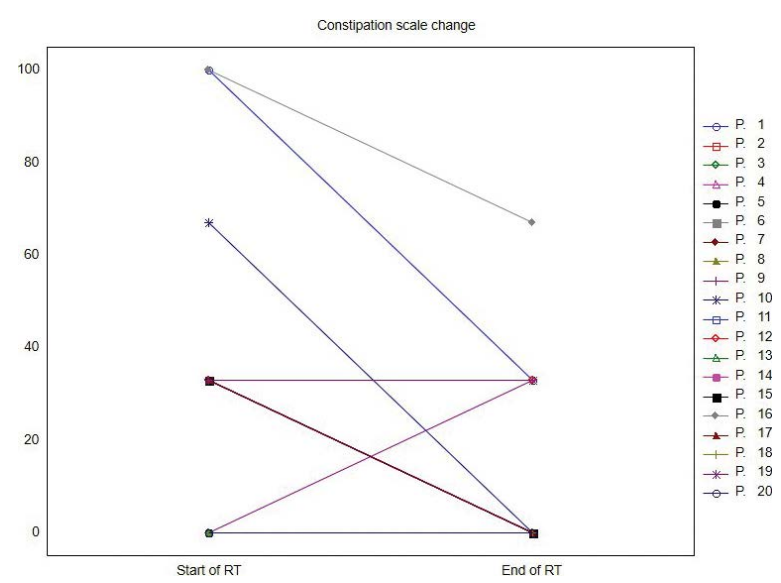

Figure 3. Change of constipation scale in time; RT — radiotherapy

tistically significant decrease in mean of global health status/quality of life assessed in the EORTC QLQ-C30 scale, from $62.25 \pm 13.12$ at the beginning of adjuvant radiotherapy to $55.85 \pm 14.68$ at the end of treatment $(p=0.047$ ) (Fig. 1).

In the EORTC QLQ-C30 symptoms scales, statistically significant differences between the onset and the end of treatment were found in three scales. Mean appetite loss score was higher at the onset of treatment than compared to its value after EBRT, $19.9 \pm 27.33$ vs $11.6 \pm 19.52$ ( $p=0.043$ ) (Fig. 2), similarly as the mean constipation score, $29.85 \pm 30.40$ vs $11.6 \pm 19.52$ ( $p=0.013$ ) (Fig. 3). Mean diarrhoea symptom scale increased from $16.55 \pm 20.16$ to $56.75 \pm 36.10(p=0.001)$ (Fig.4).There was no statistically significant difference between groups with lymphadenectomy performed and not performed in EORTC QLQ-C30 mean of global health status/quality of life, mean appetite loss scale score, mean constipation scale score and mean diarrhoea symptom scale score. Analysis of comorbidities also showed no differences between subgroups in those scales (Tab. 4). No statistically significant differences were found in other EORTC QLQ-C30 symptoms scales (Tab. 5).

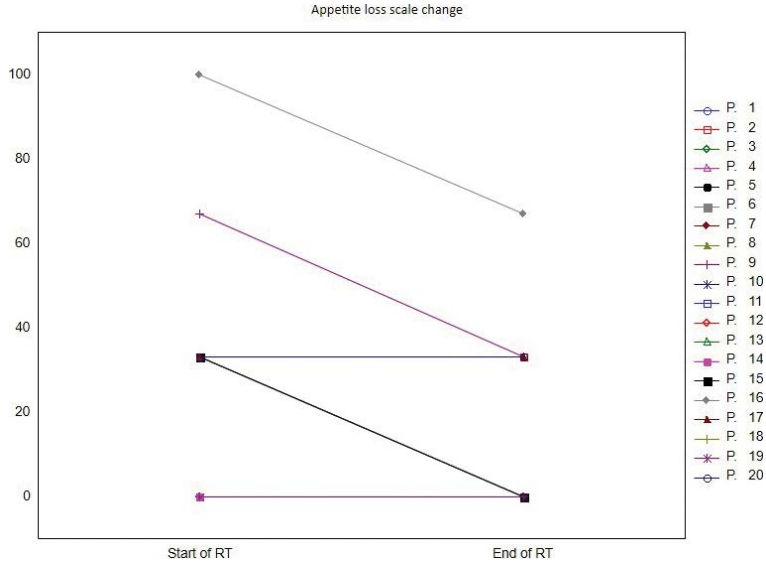

Figure 2. Change of appetit loss scale in time; RT — radiotherapy

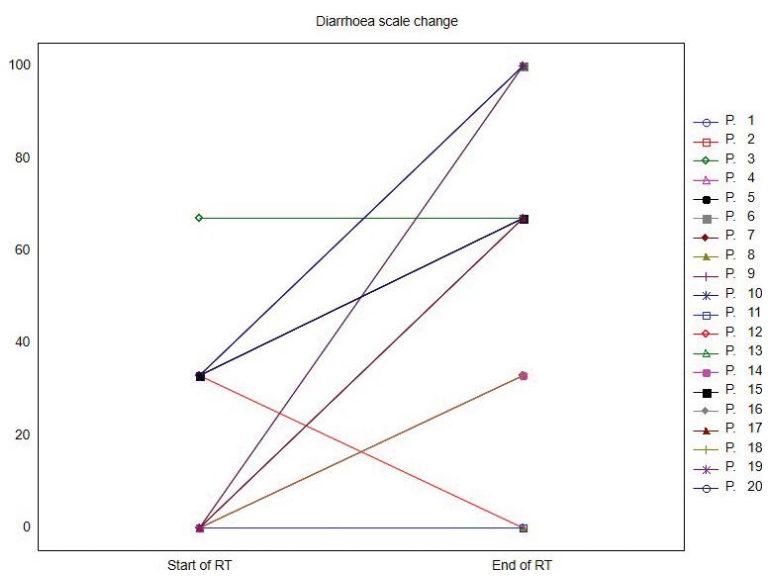

Figure 4. Change of diarrhoea scale in time; RT — radiotherapy

In EORTC QLQ-EN24 symptoms scales, gastrointestinal symptoms scores were higher at the end of treatment, with a mean of $26.45 \pm 22.76$ than compared to $14.30 \pm 16.52$ at the beginning of EBRT ( $p=0.003$ ) (Fig. 5). No statistically significant differences were observed in mean urological symptoms score and mean pain in the back and pelvis score, however, the trend toward higher score was clear. The mean urological symptoms score was higher at the end of treatment $35.80 \pm 31.50$ compared to $25.05 \pm 22.48$ at the beginning $(p=0.076)$ (Fig. 6). The mean pain in the back and pelvis score at the beginning and after EBRT combined with HDR BT were $23.20 \pm 21.89$ and $34.85 \pm 25.39(p=0.103)$, however subgroup analysis showed differences over time between subgroups with a medical history of diabetes mellitus (DM) and with no history of DM. No differences between patients with or without the medical history of DM were found in gastrointestinal symptoms scale and mean urological symptoms scale. There were no differences between subgroups with or with no medical history of hypertension or previously lymphadenectomy performed (Tab. 6). Lymphoedema symptom scale, poor 
Table 4. EORTC QLQ C-30 - differences between groups

\begin{tabular}{|c|c|c|c|c|c|}
\hline \multirow[b]{2}{*}{ EORTC QLQ-C30 scales } & \multicolumn{2}{|c|}{ Questionnaire timepoints } & \multicolumn{3}{|l|}{ p value } \\
\hline & $\begin{array}{l}\text { Start of treatment } \\
\text { Mean }( \pm \text { SD) }\end{array}$ & $\begin{array}{l}\text { End of treatment } \\
\text { Mean }( \pm \text { SD) }\end{array}$ & Changes over time & $\begin{array}{l}\text { Difference between } \\
\text { groups }\end{array}$ & $\begin{array}{l}\text { Difference between } \\
\text { groups over time }\end{array}$ \\
\hline \multicolumn{6}{|c|}{ Global health status/quality of life scale } \\
\hline \multicolumn{6}{|c|}{ Lymphadenectomy performed } \\
\hline Yes $(n=11)$ & $62.27( \pm 15.95)$ & $59.82( \pm 14.86)$ & \multirow{2}{*}{0.039} & \multirow{2}{*}{0.402} & \multirow{2}{*}{0.130} \\
\hline No $(n=7)$ & $63.29( \pm 9.53)$ & $48,86( \pm 14.21)$ & & & \\
\hline \multicolumn{6}{|l|}{ Diabetes mellitus } \\
\hline Yes $(n=6)$ & $65.5( \pm 8.24)$ & $58.33( \pm 17.55)$ & \multirow{2}{*}{0.105} & \multirow{2}{*}{0.483} & \multirow{2}{*}{0.889} \\
\hline No $(n=14)$ & $60.86( \pm 14.78)$ & $54.79( \pm 13.87)$ & & & \\
\hline \multicolumn{6}{|l|}{ Hypertension } \\
\hline Yes $(n=15)$ & $60.13( \pm 14.52)$ & $55.53( \pm 16.35)$ & \multirow{2}{*}{0.056} & \multirow{2}{*}{0.430} & \multirow{2}{*}{0.382} \\
\hline No $(n=5)$ & $68.6( \pm 3.58)$ & $56.8( \pm 9.31)$ & & & \\
\hline \multicolumn{6}{|c|}{ Appetite loss symptoms scale } \\
\hline \multicolumn{6}{|c|}{ Lymphadenectomy performed } \\
\hline Yes $(n=11)$ & $15.09( \pm 22.91)$ & $9( \pm 15.41)$ & \multirow{2}{*}{0.014} & \multirow{2}{*}{0.423} & \multirow{2}{*}{0.290} \\
\hline No $(n=7)$ & $28.43( \pm 35.61)$ & $14.29( \pm 26.30)$ & & & \\
\hline \multicolumn{6}{|l|}{ Diabetes mellitus } \\
\hline Yes $(n=6)$ & $26.07( \pm 29.75)$ & $16.57( \pm 21.64)$ & \multirow{2}{*}{0.056} & \multirow{2}{*}{0.092} & \multirow{2}{*}{0.592} \\
\hline No $(n=14)$ & $5.5( \pm 13.47)$ & 0 & & & \\
\hline Hypertension & & & & & \\
\hline Yes $(n=15)$ & $22.13( \pm 29.98)$ & $13.27( \pm 21.05)$ & 000 & 5010 & זרד \\
\hline No $(n=5)$ & $13.2( \pm 18.07)$ & $6.6( \pm 14.76)$ & 0.063 & 0.518 & $0.1 / 5$ \\
\hline Constipation symptoms & cale & & & & \\
\hline Lymphadenectomy perfo & & & & & \\
\hline Yes $(n=11)$ & $30.09( \pm 27.68)$ & $12( \pm 16.65)$ & م011 & 0067 & 0005 \\
\hline No $(n=7)$ & $28.57( \pm 40.55)$ & $9.57( \pm 25.32)$ & 0.011 & $0.86 /$ & 0.945 \\
\hline Diabetes mellitus & & & & & \\
\hline Yes $(n=6)$ & $27.67( \pm 25.15)$ & $5.5( \pm 13.47)$ & 7007 & 0 & 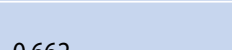 \\
\hline No $(n=14)$ & $30.79( \pm 33.23)$ & $14.21( \pm 21.51)$ & 0.007 & 0.599 & 0.662 \\
\hline Hypertension & & & & & \\
\hline Yes $(n=15)$ & $30.93( \pm 32.03)$ & $13.27( \pm 21.05)$ & 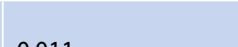 & $0<c^{2}$ & مoce \\
\hline No $(n=5)$ & $26.6( \pm 27.97)$ & $6.6( \pm 14.76)$ & 0.011 & 0.644 & 0.864 \\
\hline Diarrhoea symptom sca & & & & & \\
\hline Lymphadenectomy perfo & & & & & \\
\hline Yes $(n=11)$ & $18.09( \pm 22.90)$ & $51.55( \pm 34.64)$ & POP & 0707 & \\
\hline No $(n=7)$ & $18.86( \pm 17.64)$ & $57.29( \pm 41.82)$ & $<0.001$ & 0.792 & 0.768 \\
\hline Diabetes mellitus & & & & & \\
\hline Yes $(n=6)$ & $11( \pm 17.04)$ & $50( \pm 54.77)$ & 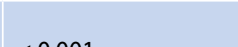 & ( & ברחת \\
\hline No $(n=14)$ & $18.93( \pm 21.50)$ & $59.64( \pm 26.86)$ & $<0.001$ & 0.455 & 0.923 \\
\hline Hypertension & & & & & \\
\hline Yes $(n=15)$ & $15.47( \pm 21.29)$ & $55.6( \pm 37.17)$ & م & ת & nom \\
\hline No $(n=5)$ & $19.8( \pm 18.07)$ & $60.2( \pm 36.56)$ & $<0.001$ & 0.722 & 0.989 \\
\hline
\end{tabular}

EORTC — European Organization for Research and Treatment of Cancer; SD — standard deviation 
Table 5. Results of QLQ C-30 - symptoms scales

\begin{tabular}{|l|l|l|l|}
\hline $\begin{array}{l}\text { EORTC symptoms } \\
\text { scales }\end{array}$ & $\begin{array}{l}\text { Start of } \\
\text { treatment } \\
\text { Mean }( \pm \text { SD) }\end{array}$ & $\begin{array}{l}\text { End of } \\
\text { treatment } \\
\text { Mean }( \pm \text { SD) }\end{array}$ & p value \\
\hline Fatigue & $40.4( \pm 22.72)$ & $38.15( \pm 20.65)$ & 0.514 \\
\hline Nausea and vomiting & $14.2( \pm 17.29)$ & $12,55( \pm 17.85)$ & 0.784 \\
\hline Pain & $22.4( \pm 17.22)$ & $28.3( \pm 21.70)$ & 0.197 \\
\hline Dyspnoea & $19.95( \pm 25.17)$ & $13.25( \pm 19.88)$ & 0.138 \\
\hline Insomnia & $45.0( \pm 37.97)$ & $41.55( \pm 28.48)$ & 0.433 \\
\hline Appetite loss & $19.9( \pm 27.33)$ & $11.6( \pm 19.52)$ & 0.043 \\
\hline Constipation & $29.85( \pm 30.40)$ & $11.6( \pm 19.52)$ & 0.013 \\
\hline Diarrhoea & $16.55( \pm 20.16)$ & $56.75( \pm 36.10)$ & 0.001 \\
\hline Financial difficulties & $11.6( \pm 19.52)$ & $13.3( \pm 22.71)$ & 0.423 \\
\hline
\end{tabular}

EORTC - European Organization for Research and Treatment of Cancer; SD — standard deviation

Gastrointestinal symptoms scale chang

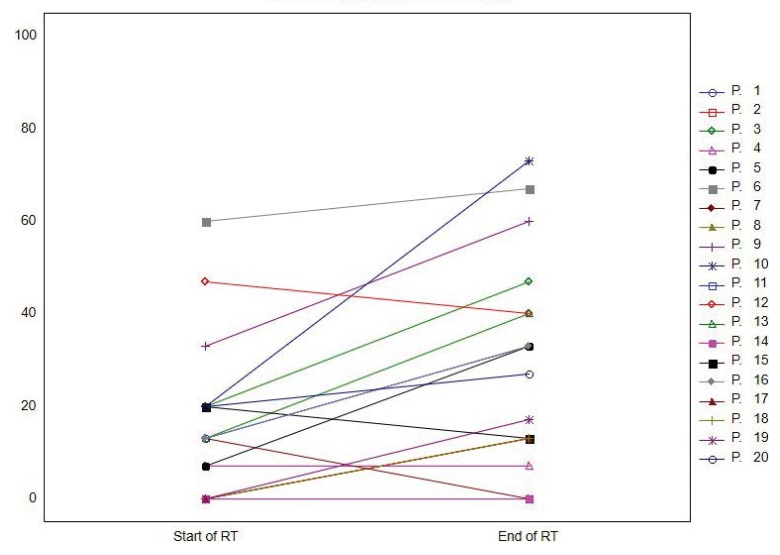

Figure 5. Change of urological symptoms scale in time; RT — radiotherapy

Urological symptoms scale change

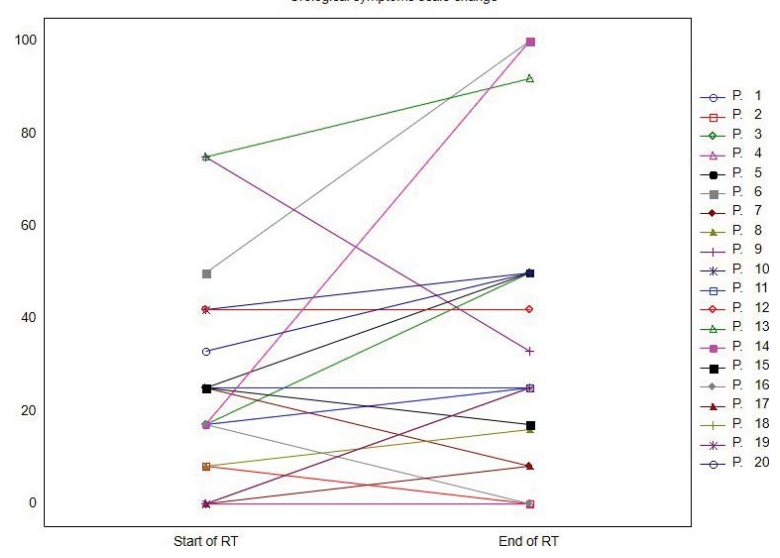

Figure 6. Change of gastrointestinal symptoms scale in time; $\mathrm{RT}$ - radiotherapy

body image scale, tingling/numbness scale, hair loss scale, taste change scale showed no differences. The exact data of scales from EORTC QLQ-C30 and EORTC QLQ-EN24 modules are presented in Tables 3-7.

\section{DISCUSSION}

When planning EBRT, doses in organs at risk (OARs) are being calculated and approved. Maximal doses to organs and dose-volumetric histograms correlate with the risk of acute and late radiation toxicity [15]. Dose constraints, maximal doses in OARs or maximal volume of OARs that are irradiated up to particular doses, allow to control toxicity at reasonable levels [16]. Even in appropriate planned and carried radiotherapy, symptoms of acute and late radiation toxicity can be observed. Our results show that in endometrial carcinoma patients after surgery, during adjuvant radiotherapy, changes in the HRQL occurred. We found the highest differences in symptoms scales regarding gastrointestinal symptoms and diarrhoea.

The HRQL is measured in many oncological clinical trials comparing the use of adjuvant treatment and its escalation $[9,10,17]$. It allows us to better identify potential factors that worsen and improve $\mathrm{HRQL}$ and to prognose and calculate the impact of treatment on HRQL. Appropriate prognosis of changes in the HRQL allows for optimal modification of the treatment in an individual patient $[9,10,17]$.

The reports describing the influence the mode of surgery on the HRQL in endometrial carcinoma patients are present in the literature. The authors confirmed that minimally invasive surgery (robotic, laparoscopic) not only shortens postoperative period but also results in a better quality of life of patients compared to open surgery [18].

The HRQL was also reported in many trials regarding adjuvant radiotherapy in endometrial carcinoma patients. The EORTC QLQ-C30 questionnaire to assess the $\mathrm{HRQL}$ was used in many well-known trials $[10,17]$, but the EORTC QLQ-EN24 module for endometrial carcinoma patients is a relatively new tool with only a few trials reported recently $[11,19]$. In the PORTEC-1 trial, comparing the use of EBRT with no adjuvant treatment, EBRT was associated with long-term urinary and bowel symptoms and lower physical and role-physical functioning [9]. The results of the PORTEC-2 trial showed that vaginal brachytherapy alone provides better HRQL then EBRT. In the PORTEC-2 for HRQL analysis, like in our study, the EORTC QLQ-C30 questionnaire was used, but no endometrial can aimed module was available at that time, so some symptoms scales were used from PR25 (prostate cancer module) and OV28 (ovarian cancer module) [10]. In the PORTEC-3 trial, HRQL was measured with EORTC QLQ-C30 with the cervix carcinoma module with chemotherapy and neuropathy subscales of the ovarian carcinoma module. This analysis of $\mathrm{HRQL}$ in that trial showed, that adjuvant chemotherapy given during and after pelvic radiotherapy relates to higher patient-reported symptoms, as well as with decreased level of patient functioning and HRQL compared with radiotherapy alone [17]. 


\begin{tabular}{|c|c|c|c|c|c|}
\hline \multirow[b]{2}{*}{ EORTC QLQ-EN24 scales } & \multicolumn{2}{|c|}{ Questionnaire timepoints } & \multicolumn{3}{|l|}{ p value } \\
\hline & $\begin{array}{l}\text { Start of treatment } \\
\text { Mean }( \pm \text { SD) }\end{array}$ & $\begin{array}{l}\text { End of treatment } \\
\text { Mean }( \pm \text { SD) }\end{array}$ & Changes over time & $\begin{array}{l}\text { Difference between } \\
\text { groups }\end{array}$ & $\begin{array}{l}\text { Difference between } \\
\text { groups over time }\end{array}$ \\
\hline \multicolumn{6}{|c|}{ Gastrointestinal symptoms scores } \\
\hline \multicolumn{6}{|c|}{ Lymphadenectomy performed } \\
\hline Yes $(n=11)$ & $14.45( \pm 15.19)$ & $23.55( \pm 21.23)$ & \multirow{2}{*}{0.006} & \multirow{2}{*}{0.443} & \multirow{2}{*}{0.394} \\
\hline No $(n=7)$ & $18.14( \pm 19.84)$ & $34.29( \pm 27.52)$ & & & \\
\hline \multicolumn{6}{|l|}{ Diabetes mellitus } \\
\hline Yes $(n=6)$ & $14.5( \pm 23.61)$ & $27.33( \pm 33.68)$ & \multirow{2}{*}{0.006} & \multirow{2}{*}{0.934} & \multirow{2}{*}{0.903} \\
\hline No $(n=14)$ & $14.21( \pm 13.57)$ & $26.07( \pm 17.90)$ & & & \\
\hline \multicolumn{6}{|l|}{ Hypertension } \\
\hline Yes $(n=15)$ & $13.67( \pm 16.40)$ & $24.2( \pm 22.07)$ & \multirow{2}{*}{0.003} & \multirow{2}{*}{0.555} & \multirow{2}{*}{0.440} \\
\hline No $(n=5)$ & $16.2( \pm 18.67)$ & $33.2( \pm 26.10)$ & & & \\
\hline \multicolumn{6}{|c|}{ Urological symptoms score } \\
\hline \multicolumn{6}{|c|}{ Lymphadenectomy performed } \\
\hline Yes $(n=11)$ & $29.64( \pm 24.82)$ & $37.91( \pm 32)$ & \multirow{2}{*}{0.143} & \multirow{2}{*}{0.851} & \multirow{2}{*}{0.736} \\
\hline No $(n=7)$ & $25( \pm 18.06)$ & $38( \pm 35.70)$ & & & \\
\hline \multicolumn{6}{|l|}{ Diabetes mellitus } \\
\hline Yes $(n=6)$ & $20.83( \pm 21.67)$ & $36( \pm 35.30)$ & \multirow{2}{*}{0.085} & \multirow{2}{*}{0.813} & \multirow{2}{*}{0.638} \\
\hline No $(n=14)$ & $26.86( \pm 23.37)$ & $35.71( \pm 31.17)$ & & & \\
\hline \multicolumn{6}{|l|}{ Hypertension } \\
\hline Yes $(n=15)$ & $26.13( \pm 23.53)$ & $37.73( \pm 34.13)$ & \multirow{2}{*}{0.175} & \multirow{2}{*}{0.638} & \multirow{2}{*}{0.811} \\
\hline No $(n=5)$ & $21.8( \pm 21.07)$ & $30( \pm 24.12)$ & & & \\
\hline \multicolumn{6}{|c|}{ Pain in back and pelvis score } \\
\hline Lymphadenectomy perforn & ned & & & & \\
\hline Yes $(n=11)$ & $21.09( \pm 22.45)$ & $39.27( \pm 29.23)$ & م0०6 & ב007 & \\
\hline No $(n=7)$ & $28.43( \pm 23.05)$ & $33.14( \pm 19.34)$ & 0.086 & 0.952 & 0.297 \\
\hline Diabetes mellitus & & & & & \\
\hline Yes $(n=6)$ & $33.17( \pm 21.19)$ & $27.67( \pm 25.15)$ & 0730 & 094 & 000 \\
\hline No $(n=14)$ & $18.93( \pm 21.50)$ & $37.93( \pm 25.78)$ & 0.238 & 0.840 & 0.040 \\
\hline Hypertension & & & & & \\
\hline Yes $(n=15)$ & $19.8( \pm 16.73)$ & $35.4( \pm 26.70)$ & & & \\
\hline No $(n=5)$ & $33.4( \pm 33.50)$ & $33.2( \pm 23.69)$ & 0.240 & 0.598 & 0.228 \\
\hline
\end{tabular}

EORTC - European Organization for Research and Treatment of Cancer; SD - standard deviation

The significance of HRQL decrease during any treatment proposed to patients is relevant in clinical practice. In our analysis, despite a small group of patients, the impact of combined EBRT and HDR BT on HRQL is clear. What is more, further enrollment to our study may allow us to find dosimetric and clinical risk factors linked to decreases HQRL during adjuvant treatment.

\section{CONCLUSIONS}

Patients who receive adjuvant radiotherapy have decreased quality of life during treatment with higher reported gastrointestinal symptoms.

The potential risk of treatment-related toxicity should be considered during the treatment planning process in order to minimize the deterioration of $\mathrm{HRQL}$. 
Table 7. Results of EN-24 - symptoms scales

\begin{tabular}{|l|l|l|l|}
\hline $\begin{array}{l}\text { EORTC symptoms } \\
\text { scales }\end{array}$ & $\begin{array}{l}\text { Start of } \\
\text { treatment } \\
\text { Mean }( \pm \text { SD) }\end{array}$ & $\begin{array}{l}\text { End of } \\
\text { treatment } \\
\text { Mean }( \pm \text { SD) }\end{array}$ & p value \\
\hline Lymphoedema & $29.95( \pm 25.23)$ & $28.20( \pm 23.58)$ & 0.529 \\
\hline Urological symptoms & $25.05( \pm 22.48)$ & $35.80( \pm 31.50)$ & 0.076 \\
\hline $\begin{array}{l}\text { Gastrointestinal } \\
\text { symptoms }\end{array}$ & $14.30( \pm 16.52)$ & $26.45( \pm 22.76)$ & 0.003 \\
\hline Poor body image & $26.35( \pm 26.23)$ & $27.3( \pm 22.41)$ & 0.753 \\
\hline $\begin{array}{l}\text { Pain in back and } \\
\text { pelvis }\end{array}$ & $23.20( \pm 21.89)$ & $34.85( \pm 25.39)$ & 0.103 \\
\hline Tingling/numbness & $13.2( \pm 16.59)$ & $9.9( \pm 15.51)$ & 0.463 \\
\hline Muscular pain & $18.2( \pm 20.09)$ & $19.85( \pm 19.87)$ & 0.917 \\
\hline Hair loss & $11.65( \pm 22.40)$ & $16.55( \pm 20.16)$ & 0.735 \\
\hline Taste change & $11.65( \pm 22.40)$ & $13.25( \pm 19.88)$ & 0.944 \\
\hline
\end{tabular}

EORTC - European Organization for Research and Treatment of Cancer;

$\mathrm{SD}$ - standard deviation

\section{Acknowledgments}

None.

\section{Conflict of interests}

The authors declare that they have no conflict of interests.

\section{REFERENCES}

1. Didkowska J, Wojciechowska U, Czaderny K, et al. Cancer in Poland in 2017, 2019, Polish National Cancer Registry. http://onkologia.org. $\mathrm{pl} / \mathrm{k} /$ baza-on-line/ (2020-05-25)

2. Bokhman JV. Two pathogenetic types of endometrial carcinoma. Gynecol Oncol. 1983; 15(1): 10-17, doi: 10.1016/0090-8258(83)90111-7, indexed in Pubmed: 6822361

3. Creasman WT, Morrow CP, Bundy BN, et al. Surgical pathologic spread patterns of endometrial cancer. A gynecologic oncology group study. Cancer. 1987; 60(Suppl 8): 2035-2041, doi: 10.1002/1097-0142(19901015)60:8+<2035::aid-cncr2820601515>3.0. co;2-8, indexed in Pubmed: 3652025.

4. Gadducci A, Cavazzana A, Cosio S, et al. Lymph-vascular space involvement and outer one-third myometrial invasion are strong predictors of distant haematogeneous failures in patients with stage I-II endometrioid-type endometrial cancer. Anticancer Res. 2009; 29(5): 1715-1720, indexed in Pubmed: 19443392.

5. Colombo N, Creutzberg C, Amant F, et al. ESMO-ESGO-ESTRO Consensus Conference on Endometrial Cancer: diagnosis, treatment and follow-up. Ann Oncol. 2016; 27(1): 16-41, doi: 10.1093/annonc/mdv484, indexed in Pubmed: 26634381.

6. Creutzberg C, Putten Wv, Koper P, et al. PORTEC Study Group. Surgery and postoperative radiotherapy versus surgery alone for patients with stage-1 endometrial carcinoma: multicentre randomised trial. The Lancet. 2000; 355(9213): 1404-1411, doi: 10.1016/s0140-6736(00)02139-5.

7. Kong A, Johnson N, Kitchener HC, et al. Adjuvant radiotherapy for stage I endometrial cancer: an updated Cochrane systematic review and meta-analysis. J Natl Cancer Inst. 2012; 104(21): 1625-1634, doi: 10.1093/jnci/djs374, indexed in Pubmed: 22962693.

8. Wortman BG, Creutzberg CL, Putter H, et al. PORTEC Study Group. Ten-year results of the PORTEC-2 trial for high-intermediate risk endometrial carcinoma: improving patient selection for adjuvant therapy. Br J Cancer. 2018; 119(9): 1067-1074, doi: 10.1038/s41416-018-0310-8, indexed in Pubmed: 30356126.

9. Nout RA, van de Poll-Franse LV, Lybeert MLM, et al. Long-term outcome and quality of life of patients with endometrial carcinoma treated with or without pelvic radiotherapy in the post operative radiation therapy in endometrial carcinoma 1 (PORTEC-1) trial. J Clin Oncol. 2011; 29(13): 1692-1700, doi: 10.1200/JCO.2010.32.4590, indexed in Pubmed: 21444867.

10. Nout RA, Putter $H$, Jürgenliemk-Schulz IM, et al. Five-year quality of life of endometrial cancer patients treated in the randomised Post Operative Radiation Therapy in Endometrial Cancer (PORTEC-2) trial and comparison with norm data. Eur J Cancer. 2012; 48(11): 1638-1648, doi: 10.1016/j.ejca.2011.11.014, indexed in Pubmed: 22176868.

11. Stukan M, Zalewski K, Mardas M, et al. Independent psychometric validation of European Organization for Research and Treatment of Cancer Quality of Life Questionnaire-Endometrial Cancer Module (EORTC QLQ-EN24). Eur J Cancer Care (Engl). 2018; 27(1), doi: 10.1111/ecc.12639, indexed in Pubmed: 28058740.

12. Greimel E, Nordin A, Lanceley A, et al. EORTC Quality of Life Group. Psychometric validation of the European Organisation for Research and Treatment of Cancer Quality of Life Questionnaire-Endometrial Cancer Module (EORTC QLQ-EN24). Eur J Cancer. 2011; 47(2): 183-190, doi: 10.1016/j.ejca.2010.08.014, indexed in Pubmed: 20851597.

13. Leppert W, Gottwald L, Forycka M. Clinical practice recommendations for quality of life assessment in patients with gynecological cancer. Prz Menopauzalny. 2015; 14(4): 271-282, doi: 10.5114/pm.2015.56539, indexed in Pubmed: 26848300.

14. Aaronson NK, Ahmedzai S, Bergman B, et al. The European Organization for Research and Treatment of Cancer QLQ-C30: a quality-of-life instrument for use in international clinical trials in oncology. J Natl Cancer Inst. 1993; 85(5): 365-376, doi: 10.1093/jnci/85.5.365, indexed in Pubmed: 8433390.

15. Stanic S, Mayadev JS. Tolerance of the small bowel to therapeutic irradiation: a focus on late toxicity in patients receiving para-aortic nodal irradiation for gynecologic malignancies. Int J Gynecol Cancer. 2013; 23(4): 592-597, doi: 10.1097/IGC.0b013e318286aa68, indexed in Pubmed: 23615570.

16. Bentzen SM, Constine LS, Deasy JO, et al. Quantitative Analyses of Normal Tissue Effects in the Clinic (QUANTEC): an introduction to the scientific issues. Int J Radiat Oncol Biol Phys. 2010; 76(Suppl 3): S3-S9, doi: 10.1016/j. ijrobp.2009.09.040, indexed in Pubmed: 20171515.

17. de Boer SM, Powell ME, Mileshkin L, et al. PORTEC study group. Toxicity and quality of life after adjuvant chemoradiotherapy versus radiotherapy alone for women with high-risk endometrial cancer (PORTEC-3): an open-label, multicentre, randomised, phase 3 trial. Lancet Oncol. 2016; 17(8): 1114-1126, doi: 10.1016/S1470-2045(16)30120-6, indexed in Pubmed: 27397040.

18. Ferguson SE, Panzarella T, Lau S, et al. Prospective cohort study comparing quality of life and sexual health outcomes between women undergoing robotic, laparoscopic and open surgery for endometrial cancer. Gynecol Oncol. 2018; 149(3): 476-483, doi: 10.1016/j.ygyno.2018.04.558, indexed in Pubmed: 29681461.

19. Papathemelis T, Scharl S, Hipp M, et al. Quality of life and oncological outcome in endometrial cancer patients after vaginal brachytherapy: comparison of two dosing schemes. Arch Gynecol Obstet. 2019; 299(2): 507-514, doi: 10.1007/s00404-018-4951-x, indexed in Pubmed: 30357499. 